Área Abierta. Revista de comunicación audiovisual y publicitaria ISSN: 2530-7592 / ISSNe: 1578-8393

\title{
Bajo los techos de París (René Clair, 1930): la irrupción del sonido en la representación del espacio urbano parisino
}

\author{
Alba Navarro Herrera ${ }^{1}$
}

Recibido: 11 de abril de 2019 / Aceptado: 29 de enero de 2020

Resumen. René Clair emprende la filmación de su primera película no muda, Bajo los techos de París (Sous les toits de Paris, 1930), en pleno fenómeno de implantación de la tecnología sonora en el cine. El relato presentado por el cineasta muestra, a través de distintos lugares típicamente parisinos, cómo se desarrollan las relaciones humanas en un barrio popular. Este artículo aborda el estudio de los diferentes escenarios recreados en los sets de rodaje de Épinay y de las ingeniosas soluciones sonoras llevadas a cabo por el director en un periodo decisivo para la evolución del arte cinematográfico.

Palabras clave: René Clair; Bajo los techos de París; tecnología sonora; espacio urbano; cine francés; historia del cine

\section{[en] Under the Roofs of Paris (René Clair, 1930): The Irruption of Sound into the Parisian Urban Space Representation}

\begin{abstract}
René Clair undertakes the filming of his first non-silent film, Under the Roofs of Paris (Sous les toits de Paris, 1930), during the phenomenon of the implantation of sound technology in cinema. The story presented by the filmmaker shows, using typical Parisian places, how human relationships are developed on a slum. This paper approaches the study of the various settings recreated at the Épinay film sets and the ingenious sound solutions implemented by the film director on a decisive period for the evolution of cinematographic art.
\end{abstract}

Key words: René Clair; Under the Roofs of Paris; sound technology; urban space; French cinema; history of cinema

Sumario. 1. Introducción. 2. Estado de la cuestión. 3. Alcance de la investigación y planteamiento metodológico. 4. París en el cine de los años treinta. 5. La ciudad evocada en Bajo los techos de París. 6. Conclusiones. 7. Bibliografía.

Cómo citar. Navarro Herrera, Alba (2020). Bajo los techos de París (René Clair, 1930): la irrupción del sonido en la representación del espacio urbano parisino. Área Abierta. Revista de comunicación audiovisual y publicitaria 20 (1), 9-25, https://dx.doi.org/10.5209/arab.64112

\footnotetext{
Universidad de Málaga (España)

E-mail:albanavarro@uma.es
} 


\section{Introducción}

El cine producido durante la década de 1930 se encuentra irremediablemente vinculado a los progresos tecnológicos: la irrupción del sonido marcó un antes y un después en la historia del séptimo arte determinando decisivamente el futuro de esta disciplina, cuyo rumbo se encontraría envuelto en un clima en el que abundarían tanto detractores como impulsores de dichas novedades ${ }^{2}$. La industria francesa padecía en aquellos años una deficiente inversión económica, lo que supuso la compra y el alquiler de equipos estadounidenses y alemanes. Por su parte, Léon Gaumont se encontraba trabajando con dos ingenieros daneses, Petersen y Poulsen, en un procedimiento de sonorización que llegaría de manera tardía.

En 1928, la guerra de patentes desembocó en un importante acuerdo: dos empresas americanas, Western Electric y RCA, y una alemana, Tobis Klangfilm, "definen las normas técnicas del nuevo medio de comunicación y se reparten esa fabulosa tarta que supuso el equipamiento de decenas de miles de salas en el mundo entero con un material costoso y delicado" (Jeancolas, 1997: 31). En Épinay, de técnica alemana, y en Billancourt, de técnica americana, dispondrían de nuevos estudios a partir del otoño de 1929. La primera obra en francés sonora apareció el veintidós de octubre de ese mismo año bajo la dirección de Tony Lekain y Gaston Ravel. Su título era El collar de la reina (Le collier de la reine). Se trataba de "un filme mudo al que se le añadió, de una manera desastrosa, un acompañamiento musical y algunas escenas dialogadas" (Jeancolas, 1997: 31). Nueve días después, se estrenó Las tres máscaras (Les trois masques) de André Hugon, rodada en Inglaterra en el estudio de Twickenham. La película supuso una regresión, ya que la puesta en escena se diluía a causa de los imperativos técnicos. En cualquier caso, el aumento en la producción fue más que evidente; los datos ofrecidos por Barroso (2010) al respecto resultan reveladores: en 1929 había unas cincuenta películas; en 1931, unas cien; y en 1933, más de ciento cincuenta.

En el año 1932, cuando el sector cinematográfico francés sufría también las consecuencias de la Gran Depresión, los Estudios Paramount de Joinville se convirtieron en estudios de doblaje; su actividad anterior, filmar versiones simultáneas de cada película en diferentes idiomas, había resultado un absoluto fracaso económico. Por otra parte, la compañía Tobis-Klangfilm, instalada en Épinay, se enfrentaba en las salas europeas a la hegemonía del cine estadounidense como lo hacía en los tribunales por las patentes de los equipos de sonido. La relación laboral de René Clair con dicha empresa dio lugar a la filmación de Bajo los techos de París. Según Barroso, quien nos ilustra sobre estos acontecimientos, "el cineasta era sinónimo de prestigio para la productora, pero el dominio nazi expulsó al director a quien consideraba un peligro para la doctrina nacionalsocialista" (2010: 8). En 1933, se multiplicaron las quiebras económicas. En 1934, la Gaumont se arruinó y, dos años más tarde, la PathéNatan. A pesar de estas circunstancias, a consecuencia de malas gestiones en los procesos de producción, distribución y exhibición, la calidad de las películas no se vio afectada. Distintos a estos sucesos, otros eventos del contexto histórico aventuraban un tiempo de gran complejidad:

En relación con esta cuestión, es pertinente señalar que figuras como Edison y Pathé ya trabajaron para obtener la sincronización de las imágenes con discos o rodillos gramofónicos, aunque sin mayor trascendencia. 
Esas películas sonoras, con las estrellas que las acompañaban, instituyeron un tipo de cine que contenía en sí mismo el carácter y las aspiraciones más puramente francesas - a menudo de un modo cáustico, como en los hoscos filmes que Marcel Carné realizó durante los años treinta, situados en los distritos marginales de $\mathrm{Pa}$ rís-, en una época en la que el nacionalismo francés estaba listo para proyectarse en caída libre y su poder colonial se desmoronaba progresivamente mientras el fascismo europeo iniciaba su consolidación. (Barber, 2006: 41)

La industria francesa de los años treinta fue frágil, pero no por ello menos válida: esta época dio lugar a la creación de grandes clásicos y a la confluencia de profesionales de orígenes diversos, como los rusos de Montreuil o los exiliados por el régimen nazi; así, directores de gran prestigio como Billy Wilder, Fritz Lang o Max Ophüls dejaron su huella en el cine francés. De igual modo, destacan en este periodo, junto al propio René Clair, los cineastas Jean Vigo, Marcel Carné, Sacha Guitry y Jean Renoir. A estas figuras se suman en el panorama actoral Michel Simon, Louis Jouvet, Arletty o Jean Gabin. En lo relativo a otras ramas del ámbito cinematográfico (técnicos, decoradores o cámaras), encontramos nombres tan significativos como el de Curt Courant o Eugen Schüfftan.

\section{Estado de la cuestión}

Durante el proceso de búsqueda de referencias documentales, se han encontrado numerosas investigaciones llevadas a cabo en torno al tema en el que se enmarca este artículo, aunque con enfoques de análisis muy diversos. Esta compleja y extensa bibliografía es fruto del gran interés académico que ha suscitado en los últimos años la relación existente entre el cine y la ciudad y, concretamente, la representación de la imagen de París en la gran pantalla. Debido a la imposibilidad de reflejar en estas páginas todas las fuentes consultadas, nos centramos en señalar algunas de las más significativas.

En el ámbito internacional, uno de los trabajos de mayor relevancia ha sido desarrollado por Barber (2006), quien indaga en los orígenes de la ciudad fílmica, estudia el espacio urbano en el cine europeo y en Japón y, por último, dedica un capítulo a la ciudad digital y el cine. Aquí, el autor se refiere a un entorno versátil cuya configuración se encuentra basada en un diálogo entre opuestos que, a su vez, se complementan:

La ciudad fílmica compone un entramado de imagen y lenguaje, de vida y muerte. Incesantemente asume y descarta sus múltiples figuras y manifestaciones $\mathrm{y}$, a través de su último matiz monocromo o de su lívido píxel, su eje vital permanece en contradicción: desde los orígenes de la imagen cinemática, todos y cada uno de los propósitos y de las estrategias de los innumerables creadores de la ciudad fílmica han sido objeto de réplica y de rechazo. (Barber, 2006: 13)

Dentro de la trama, la ciudad puede llegar a ser considerada como un personaje más, pudiendo ostentar el mismo valor argumental que cualquier otro. Además, tiene la capacidad de expresar conceptos vinculados a fenómenos sociales o etapas históricas, y de definir el carácter y las circunstancias que forman parte de la vida de los 
personajes (Camarero, 2013). Pero tanto en el cine como en la vida no solo la ciudad define al individuo, pues es el propio individuo el que influye en la ciudad y cambia su entorno. El espacio urbano va transformando su aspecto al tiempo en que conserva aquellos elementos emblemáticos que representan su historia, convirtiéndose, de esta manera, en un paisaje de gran riqueza visual (Navarro, 2015). Estas afirmaciones nos llevan a la idea de que la metrópolis, en continuo diálogo con las personas, se convierte para el cineasta en un lugar de descubrimiento:

Entonces se puede concebir ese mismo espacio urbano como un reducto humano sujeto a las variaciones que su propia imagen desencadena y promueve. Como cuestión figurativa, la ciudad ofrece a los cineastas una vasta zona de búsqueda y experimentación. Permite que el cine funcione como recorrido, como relevamiento, como captor de índices. Y propone un desafío: el de buscar (y encontrar) historias. (Ferré, 2001: 58)

Asimismo, resulta destacable la propuesta crítica de Yeste (1994-95), quien explica que el cine se constituye como una fuente documental que reconstruye la historia urbana de la ciudad. Mientras que en los rodajes en escenarios naturales se exhibe de un modo inequívoco el entorno urbano en el que tuvo lugar una filmación, con los escenarios irreales o reconstruidos se expresa un tipo de concepción estética. Indagando en otras áreas de investigación, Villanueva (2008) propone un análisis dual sobre las imágenes de la ciudad, desde la poesía y desde el cine, y se refiere a la existencia de un idilio entre esta y el celuloide que no parece que vaya a concluir. A tales cuestiones se suma el gran poder de influencia del séptimo arte para crear memoria colectiva a través de amplios grupos de espectadores (Kale, 2005).

Por otro lado, nombramos por el valor de sus aportaciones sobre este tema de estudio, como veremos en las siguientes páginas, a Vuillermoz (1934), Ramírez (1993) y Domínguez (1998). Y no podemos dejar de mencionar el capítulo elaborado por Hueso (2014), en el cual se reflexiona sobre las representaciones de París en el cine a lo largo de la historia. A pesar de ser un trabajo parcial en cuanto a la selección filmográfica, el autor expone su intención de ofrecer una visión global, significativa y valorativa del conjunto de filmes, cuyas visiones sobre la ciudad fluctúan entre la fantasía y la realidad:

Por una parte, se encuentra un planeamiento que concede especial importancia a la fantasía, con lo que ello conlleva de reinterpretación creativa del mundo concreto que tenemos ante nuestra cámara, pero por otra tenemos las obras presididas por un deseo de captar la realidad tal como es, de dejar en las imágenes testimonios directos de una geografía y una sociedad muy concretas. Bien es verdad que estos dos planteamientos en muchas ocasiones no se encuentran radicalmente diferenciados. (Hueso, 2014: 275)

Para terminar, nos detenemos en algunas publicaciones realizadas durante las últimas décadas en el contexto francés e íntegramente dedicadas al estudio del París cinematográfico: en primer lugar, hacemos referencia al catálogo de la exposición Paris vu par Hollywood, presentada en 2012 en la sala Saint-Jean por el departamento de exposiciones del Ayuntamiento de París y comisariada por Antoine de Baecque; en segundo lugar, citamos los libros escritos por Douchet \& Nadeau (1987) 
y por Binh (2005), y la obra coordinada por Hillairet, Lebrat, \& Rollet (1985) dedicada al cine de vanguardia.

\section{Alcance de la investigación y planteamiento metodológico}

Las líneas precedentes nos permiten conocer con más detalle el contexto del cine francés en el que se sitúa Bajo los techos de París y nos ayudan a comprender el trascendental papel que ha desempeñado la ciudad en relación con la evolución y la maduración del arte cinematográfico. Igualmente, dichas cuestiones contribuyen a delimitar los márgenes de este estudio, el cual pretende poner en evidencia las características de la configuración de la imagen de la capital francesa en el citado filme de Clair. Una imagen que suma una nueva dimensión a la experiencia del espectador: el sonido. Este importante hito hace de la película una pieza clave para entender la evolución de las representaciones de la ciudad de París en el cine. Como objetivos específicos planteamos los siguientes:

- Identificar los escenarios concebidos por René Clair y reflexionar sobre las ideas asociadas a la capital francesa.

- Analizar la vinculación entre la escenografía parisina y los distintos momentos de la acción.

- Reconocer los entornos que son utilizados para definir las características de los personajes.

- Indagar en los distintos planteamientos sonoros diseñados para la puesta en escena de la vida en la ciudad durante el desarrollo del filme.

Para cumplir con tales objetivos, ha sido necesario escoger un planteamiento metodológico basado en el análisis de contenido. Al posicionarnos en este punto, es imprescindible tener en cuenta que el objeto de estudio - el París cinematográfico- cuenta con un modelo real al que el cineasta ha podido elegir o no aproximarse. Esta circunstancia es común en este tipo de investigaciones pues "muchos análisis de contenido son verificaciones de la realidad en los que se compara el retrato de cierto grupo, fenómeno, rasgo o característica con una norma tomada de la realidad" (Wimmer \& Dominick, 2001: 137). De manera específica, se ha trabajado con un enfoque cualitativo, que ha permitido llevar a cabo una exploración exhaustiva sobre las razones que determinan la visión cinematográfica parisina proyectada por René Clair:

El análisis de contenido cualitativo consiste en un conjunto de técnicas sistemáticas interpretativas del sentido oculto de los textos. (...) no sólo se ha de circunscribir a la interpretación del contenido manifiesto del material analizado, sino que debe profundizar en su contenido latente y en el contexto social donde se desarrolla el mensaje. (Andréu, 2001: 22)

En este proceso cobra una gran importancia el papel del analista, quien al situarse ante una película comienza "un camino que lo conduce de un objeto concreto dotado de evidencia y de corporeidad, a un objeto nuevo, que deja al desnudo 
los principios de la construcción y los principios del funcionamiento del primero" (Casetti \& Di Chio, 1996: 25). Precisamente, para tomar consciencia sobre los mencionados principios nos han resultado de gran utilidad las disertaciones de Schafer (2013) sobre el concepto de paisaje sonoro, con el que se refiere a los acontecimientos escuchados y a cualquier campo de estudio acústico. En el mundo de las artes, particularmente en la música, son creados "paisajes sonoros ideales para esa otra vida, la vida de la imaginación y la reflexión psíquica” (Schafer, 2013: 20). Más recientemente, Ortiz (2015) nos habla de la capacidad de los paisajes sonoros para describir y dar sentido a un lugar. Estos, además, expresan la identidad de un espacio y, por consiguiente, de su comunidad, haciendo que se distinga de otras comunidades. De ahí que, según la autora, el sonido resulte esencial en la construcción del paisaje cinematográfico.

Por su parte, Casetti \& Di Chio (1996) nos recuerdan que las voces, los ruidos y los sonidos son los tres tipos de elementos que configuran la materia sonora de las películas. Y, al mismo tiempo, nos conducen por las tres categorías de sonidos que podemos encontrar en ellas: in — sonido diegético exterior con la fuente encuadra$\mathrm{da}$ - , off — sonido diegético exterior con la fuente no encuadrada - y over — sonido diegético interior in u off, y sonido no diegético o extradiegético-. De la misma manera, los teóricos se detienen en comentar aquellos aspectos que dan lugar a la configuración del ambiente en una obra fílmica:

El ambiente, como hemos visto, se define mediante el conjunto de todos los elementos que pueblan la trama y que actúan como su trasfondo: en otras palabras, es lo que diseña y llena la escena, más allá de la presencia identificada, relevante, activa y focalizada de los personajes. El ambiente remite a dos cosas: por un lado, al "entorno" en el que actúan los personajes, al decorado en el que se mueven; por el otro a la "situación" en la que operan, a las coordenadas espaciotemporales que caracterizan su presencia. (Casetti \& Di Chio, 1996: 176)

En definitiva, durante el visionado del filme se ha mantenido una actitud de observación minuciosa para poder identificar y analizar todos aquellos espacios que forman parte de la definición de la imagen de la ciudad, que sirven para recrear los ambientes donde trascurren los acontecimientos o para describir las características de los personajes. Todo ello, atendiendo al inédito uso de la tecnología sonora como medio de expresión creativa.

\section{París en el cine de los años treinta}

La relación entre la ciudad de París y el séptimo arte se remonta al trabajo que desarrollaron los hermanos Lumière ${ }^{3}$. Los pioneros del cine fueron los responsables de la filmación de la primera película ubicada en una localización parisina, Bassin des Tuileries $(1896)^{4}$. Con el paso del tiempo, los lugares que un día quedaron inmortali-

Ver Aubert \& Seguin (1996). Este recurso ofrece una catalogación exhaustiva de la producción de los hermanos Lumière.

4 Además de sus numerosas vistas de la capital francesa, como Champs-Élysées (1896), Place de l'Opéra (1896) o Les Invalides (1900), una de las grandes aportaciones de los hermanos Lumière fue realizar el primer gran 
zados por el cinematógrafo han mantenido su presencia en la pantalla, haciendo de la capital francesa uno de los principales enclaves filmicos a nivel internacional. Si nos situamos de lleno en la producción cinematográfica de los años treinta, observamos que París fue el escenario elegido por numerosos cineastas para emplazar sus relatos, entre los que destacan obras memorables de la historia del cine ${ }^{5}$.

Ramírez (1993) expone que la ciudad más representada por el cine americano, aparte de Nueva York, fue París, siendo su traslación a la pantalla de menor realismo que la de los escenarios estadounidenses. Esta falta de especificidad permitía que representara un decorado más genérico, el cual podía aludir a una ciudad o a una aldea europea. Según el investigador, la "calle francesa" de Warner Brothers fue reconstruida para la película Tovarich (Anatole Litvak, 1937) y su alquiler tenía un coste de dos mil quinientos dólares diarios. En cuanto a la calle más famosa, con una apariencia condicionada por las series de terror que allí fueron rodadas y que la impregnaron de un aspecto "sombrío" y "vagamente centroeuropeo", se encontraba en Universal.

En este contexto fue escrito el artículo "Comment les metteurs en scène d'Hollywood se représentent Paris et ses habitants", firmado por Émile Vuillermoz y publicado en la revista Pour vous. L'hebdomadaire du cinéma en su número doscientos setenta y siete, que data del ocho de marzo de 1934. El autor indaga en la imagen de París representada por Hollywood y, concretamente, por la película L'amour guide (Norman Taurog \& Jean Boyer, 1933) protagonizada por el popular Maurice Chevalier. Émile Vuillermoz se pregunta por las causas que llevan a la industria cinematográfica a ofrecer una imagen deformada sobre la urbe parisina y propone hacer una reflexión sobre los motivos que pueden crear en los visitantes de la ciudad este tipo de percepciones. Con la expresión "il n'y a pas de fumée sans feu!" (Vuillermoz, 1934: 3) concluye la redacción. Encontramos en esta crítica un precedente sobre el interés que suscita la imagen de la ciudad de París en el celuloide, objeto de estudio que seguiría vigente hasta nuestros días.

Por su parte, Óscar Domínguez comenta que París se incluye en "la ruta de las ciudades soñadas, de ese puñado de lugares de saudade que se puede habitar con la memoria incluso antes de haberles rendido visita" (1998: 171). Este hecho es posible gracias a un proceso de reconocimiento en gran parte debido a la capacidad de representación y fascinación del cine. Domínguez establece dos tipos de representaciones de la ciudad de París en el cine de los años treinta: la de la Ciudad de la Luz y la del Muelle de las Brumas. La primera de estas visiones se corresponde con la recreada en Hollywood por los decorados de los grandes estudios, donde la capital francesa es proyectada "como paradigma del lujo, de los placeres refinados y desenfadados por la alegría de vivir" (Domínguez, 1998: 174). La visión opuesta sería la plasmada por los cineastas franceses que, siendo autores coetáneos, trazaron una imagen más realista de la urbe, acercando su mirada al realismo poético. El teórico expresa que

trávelin de la ciudad en Panorama de la llegada del tren a la estación de Perrache (Panorama de l'arrivée en gare de Perrache pris du train, 1896).

5 Algunos títulos destacados son Boudu salvado de las aguas (Boudu sauvé des eaux, Jean Renoir, 1932), ¡Aló, París! (Allô Berlin? Ici Paris!, Julien Duvivier, 1932), L'Atalante (Jean Vigo, 1934), Margarita Gautier (Camille, George Cukor, 1936), Hotel del Norte (Hôtel du Nord, Marcel Carné, 1938), Subamos por los Campos Elíseos (Remontons les Champs-Elysées, Sacha Guitry, 1938) y Esmeralda, la zingara (The Hunchback of Notre Dame, William Dieterle, 1939). 
el cine del Frente Popular pedirá la palabra para la gente de la calle, héroes anónimos de los arrabales, los cuales son también protagonistas de las fotografías humanistas de Boubat, Cartier-Bresson o Doisneau:

Los personajes del realismo poético francés parecen que son sombras errantes en un París eternamente otoñal, que ya para siempre será de hojas muertas y en blanco y negro, buscando la solidaridad de los demás y viviendo el amor como única forma de esperanza para los espectadores. Frente a la elegante puesta en escena de los estudios de Hollywood la mirada de Renoir, Marcel Carné o Vigo intentará acercar la cultura a la calle acortando las distancias entre la realidad cotidiana y la realidad filmada, dejando fluir el azar de la vida frente al acotamiento de la trama. (Domínguez, 1998: 175-176)

En esta misma década, René Clair se erige como el impulsor del cine sonoro parisino, contando en su equipo con un profesional de gran trascendencia, el director artístico Lazare Meerson. La visión de Clair requería de unos decorados de gran realismo y estilización, siendo estas dos cuestiones compatibles. De este modo, París se convirtió en la protagonista de tres de las cuatro primeras películas sonoras que realizó: Bajo los techos de París, El millón (Le million, 1931) y Catorce de julio (Quatorze juillet, 1933). A través de ellas, el cineasta pudo proyectar una nueva imagen de la capital que dejaría su huella en el cine francés de las siguientes tres décadas (Binh, 2005).

A modo de resumen, es posible afirmar que París afianza su posición como ciudad atractiva para el planteamiento de los guiones cinematográficos más variados de aquellos años. Los directores que eligieron este versátil enclave respondían a perfiles muy diferentes: los había soñadores, activistas, con un gran ingenio o innovadores; entre todos ellos hicieron de la ciudad el ideal escenario para las historias del París de los años treinta, del París del pasado, del París fantástico, del París hipócrita o del París de novela. El cine francés en estos años se aleja de la visión vanguardista para acercarse a la mirada del realismo poético. Mientras tanto, el cine americano triunfa con la comedia y se aferra a la adaptación de grandes clásicos de la literatura. París es una ciudad en la que es posible a un mismo tiempo soñar, sobrevivir y amar. En ocasiones, sus calles, sus hogares y sus establecimientos albergan contundentes diferencias sociales, que son la base para el establecimiento de reivindicaciones de esta índole o para plantear relatos que defienden la emancipación del ser humano con respecto a los convencionalismos. En su faceta más trágica, la ciudad acoge la muerte de sus moradores. Pero, también, baila al ritmo de sus salones nocturnos, de las fiestas populares y de las veladas de las clases opulentas.

\section{La ciudad evocada en Bajo los techos de París}

\subsection{El primer proyecto sonoro de René Clair}

Según el propio René Clair en unas declaraciones recogidas por Barroso (2010), el origen de este proyecto se remonta al rodaje de una de sus películas mudas, cuando un día al caminar fuera del estudio vio a una multitud que corría para escuchar a un 
cantante callejero; esta escena le pareció conmovedora, encantadora y típicamente parisina. El teórico indica que Clair tenía debilidad por la comedia y que puede considerársele en aquellos años como el mejor director europeo del género por su capacidad para satisfacer tanto al intelectual más exigente como al espectador medio. Asimismo, hace referencia a su gran habilidad narrativa y al halo melancólico que emana de esta obra fílmica:

Bajo los techos de París, a pesar de contar una historia dramática, mantiene en todo momento ese aire de comedia elegante, sutil, capaz de combinarse con momentos trágicos sin ningún esfuerzo aparente. Hay un claro sabor nostálgico en la película, una necesidad de recuperar un pasado esplendoroso que irremediablemente ha entrado en decadencia para dar paso al mundo moderno y su prisa por devorarlo todo de una vez. (Barroso, 2010: 78)

El dos de enero de 1930 el cineasta francés emprende su primer trabajo no mudo, partiendo de la creencia de que el primer medio de expresión en el cine era la imagen, por lo que el aspecto sonoro no debía ser preponderante (Jeanne \& Ford, 1997). En relación con esta idea, es posible hablar de un sentimiento de antipatía por el invento del sonido (Barroso, 2010). En cualquier caso, su uso en la película resultó innovador y creativo. En algunas ocasiones, el diálogo de la escena enmudece de manera arbitraria para solo dejar paso al sonido extradiegético, como en el cine mudo. En otras, la palabra toma absoluto protagonismo y es capaz de narrar acontecimientos que no son perceptibles visualmente. Todas estas cuestiones muestran "una ingeniosa utilización de los recursos del sonido independientemente de la imagen y recíprocamente, para la consecución de efectos dramáticos imposibles en el teatro" (Jeanne \& Ford, 1997: 111). Jeancolas señala que, tanto en este filme -concluido en febrero de 1930 en Épinay- como en El millón, en Viva la libertad (À nous la liberté, 1931) y en Catorce de julio, la música y las canciones animan "la vida del 'pueblo' parisino, que puede ser todo lo que quiera menos realista: una visión etérea, poetizada, que seduce al mundo entero" (1997: 32).

Bajo los techos de París fue producida por la Tobis-Klangfilm, modelo de compañía que integraba procesos de producción y distribución, y cuya tecnología la erigía como el más significativo competidor europeo en sistemas sonoros con respecto a la industria americana. Precisamente, su gran capacidad de distribución internacional influiría en que la película fuera antes popular en Alemania que en Francia. Otro factor que pudo ser decisivo es señalado por Alberto Cavalcanti - como se cita en Bergfelder, Harris \& Street, 2007- al referirse a Lazare Meerson. El cineasta brasileño comenta que este, al no ser francés, fue capaz de crear una visión de París más cercana a la que tienen los extranjeros, lo que contribuyó al éxito. Dicha circunstancia y la lejanía de una visión más ligada a la realidad metropolitana tendrían relación con un inicial fracaso en Francia. Además, es preciso tener en cuenta que, tanto en esta película como en otras de la época, los sets ya contaban con características necesarias para los rodajes: temáticas, coherencia arquitectónica, escala y autenticidad (Bergfelder et al., 2007). 


\subsection{La recreación del ambiente de una calle parisina}

Los hechos relatados por Clair transcurren en la década de 1930 y retratan un París que, bajo sus techos, alberga a una gran pluralidad de tipos: cantantes, inmigrantes, ladrones, enamorados; entre ellos, un grupo de personajes forma algo más que un triángulo amoroso. Pola (Pola Illéry), una joven inmigrante polaca, es una mujer deseada por tres hombres. El primero es Albert (Albert Préjean), un cantante callejero que la ama sinceramente y que es encarcelado por error. Durante el tiempo que este pasa entre rejas, su amigo Louis (Edmond T. Gréville) entabla una relación más cercana con Pola, que termina por unirlos. Mientras tanto, Fred (Gaston Modot), líder de una banda de gánsteres, no está dispuesto a permitir que nadie perturbe sus planes. Al hilar las historias de todos los personajes, la película presenta un perfecto retrato de la vida en la ciudad, siendo este un claro reflejo del imaginario parisino:

Bajo los techos de París (Sous les toits de Paris, R. Clair, 1930) utiliza de manera magistral los nuevos recursos técnicos y estéticos derivados de la incorporación del sonido para ofrecernos un mundo no solo físico, sino también, y de manera especial, humano, que desde ese momento aparece como el paradigma de lo parisino. El uso que se hace de la música y las canciones, junto con los decorados que recrean la geografía urbana de la capital y sus barrios más populares, se convierte en soporte para presentar una realidad que, de manera paulatina, se consagrará como la imagen tópica de la ciudad. (Hueso, 2014: 275)

París desde el cielo, así comienza el relato fílmico. Los tejados de la ciudad son captados a través de diferentes planos - imagen 1-. Desde ellos se desprende el humo de las chimeneas, dando paso a las fachadas parisinas plagadas de balcones y ventanales a los que se asoman los curiosos. Podemos observar la vida de una calle en la ciudad, en la que un coro canta una canción popular, "Sous les toits de Paris". Jeanne \& Ford (1997) advierten que la canción, con música de Raoul Moretti y letra de René Nazelles, no fue ajena al éxito de la producción, por lo que René Clair, al comprobar la eficacia del uso de la música, recurrió a este elemento en sus próximos proyectos. Sobre esta cuestión, Barroso afirma que "otro de los encantos sublimes del filme es la deliciosa canción que se repite a lo largo del mismo y que nos deja el dulce y a veces amargo sabor del transcurso del tiempo" (2010: 78).

La cámara penetra en la calle captando la presencia de distintos personajes que se ubican en la zona: alguien que barre, una señora que limpia una ventana, otra asomada desde un balcón, caballeros que se arriman al coro, etc. Entonces, el cineasta presenta a una mujer: Pola, quien apoyada en el marco de una puerta terminará por incorporarse al círculo de cantores; mientras tanto, Albert anima al público a seguir entonando. Barroso, al referirse al arranque, se detiene en comentar el espectacular plano general que muestra los tejados de la ciudad y que avanza lentamente hasta llegar al personaje principal, e incide en que se trata de "un movimiento de grúa casi perfecto, y una verdadera audacia para la época" (2010: 78). Después, la cámara se desplaza verticalmente por la fachada más cercana al coro con una obvia función descriptiva. Clair presenta a cada uno de los tipos que ocupan las diferentes estancias del inmueble, para terminar nuevamente en el cielo parisino. En estos primeros momentos de la narración, el director consigue aunar con una gran sutileza los decorados del estudio y la presencia de la ciudad real: 


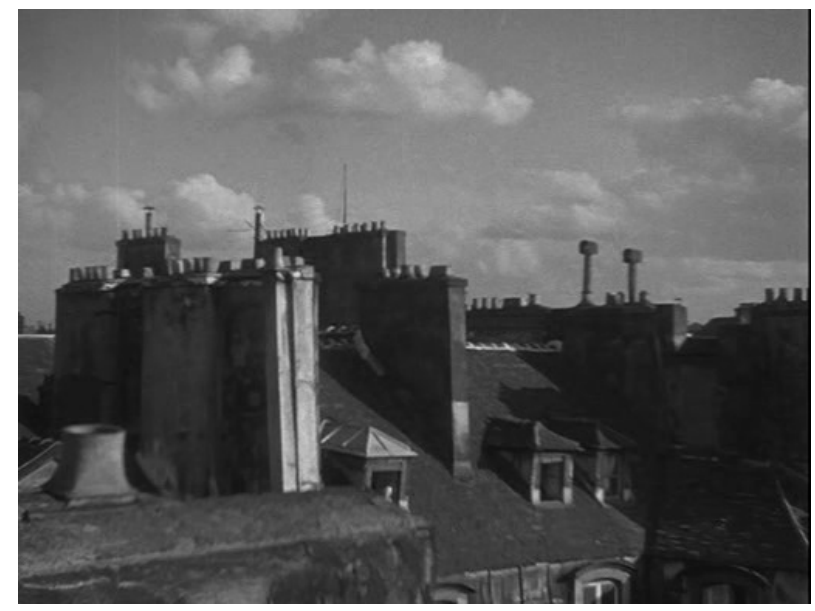

Imagen 1. [Fuente: captura de pantalla].

En esta innovadora secuencia de apertura, vemos cómo las fachadas de un set construido en el plató de exteriores de los estudios de Épinay se combinan con los auténticos espacios del París contemporáneo - en este caso el distrito vecino de Épinay - añadiendo un grado de inmediatez y realismo a la experiencia de visualización, que era completamente nueva para el cine francés ${ }^{6}$. (Bergfelder et al., 2007: 178)
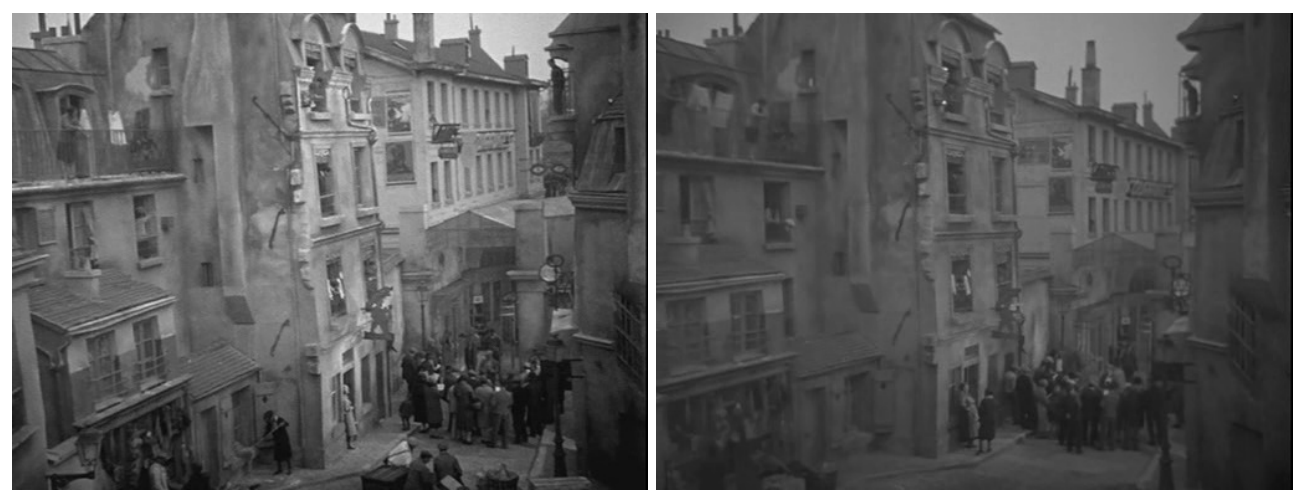

Imágenes 2 y 3. [Fuente: captura de pantalla].

René Clair concibe para la clausura un paralelismo con respecto al comienzo, aunque en este caso la secuencia se desarrolla de manera inversa, concretamente, podemos hablar de la elección de un tiempo cíclico ${ }^{7}$ (imágenes 2 y 3 ). Albert sigue

\footnotetext{
6 "In this innovative opening sequence, we see how the facades of a set built on the backlot of the Epinay studios blend with the authentic spaces of contemporary Paris - in this case the neighbouring district of Epinayadding a level of immediacy and realism to the viewing experience that was entirely new to French cinema". Traducción propia.

7 Casetti \& Di Chio (1996) explican que el tiempo cíclico está determinado por una sucesión de acontecimientos ordenados de tal modo que el punto de llegada de la serie resulta ser análogo al de origen, aunque no idéntico.
} 
siendo un cantante callejero que anima a las gentes en coro con la melodía Sous les toits de Paris. La cámara se aleja dejando atrás a los pobladores de la ciudad que, con alegría, afinan en mitad de una calle. Las fachadas quedan atrás en una estampa en la que los curiosos siguen asomados a sus balcones y ventanas. Finalmente, el cineasta sitúa la cámara en los techos de París junto al denso humo de las chimeneas.

\subsection{La representación del espacio urbano y el uso del sonido}

Las calles de la ciudad son lugares donde con ingenio, del mismo modo que Albert, pueden conseguirse algunas monedas o donde con astucia puede aprovecharse el despiste de los ciudadanos que cantan entretenidos en el coro para llevar a cabo pequeños hurtos. En las calles también se establecen algunos vendedores y quioscos a la espera del comprador transeúnte. Estas son bulliciosas durante el día y espacios solitarios durante la noche, perfectos para que los ladrones y delincuentes, como los liderados por Fred, puedan operar sin llamar la atención. Albert y Pola vagarán en la noche por las calles de París. Clair filma a través de diversos planos detalle el paso de sus pies por los adoquines de la ciudad, donde solo la luz de algunas farolas alumbra los desérticos rincones en la nocturnidad. El cineasta inserta con una sobreimpresión la imagen de un reloj para anunciar la medianoche y, posteriormente, la una de la madrugada. El gran vacío que envuelve a los jóvenes contrasta profundamente con los alegres momentos de confluencia que tienen lugar durante del día gracias a la música. Para Douchet \& Nadeau (1987), la idea de un París alegre al mismo tiempo que triste es expresada de manera exagerada a través de los decorados de Lazare Meerson.
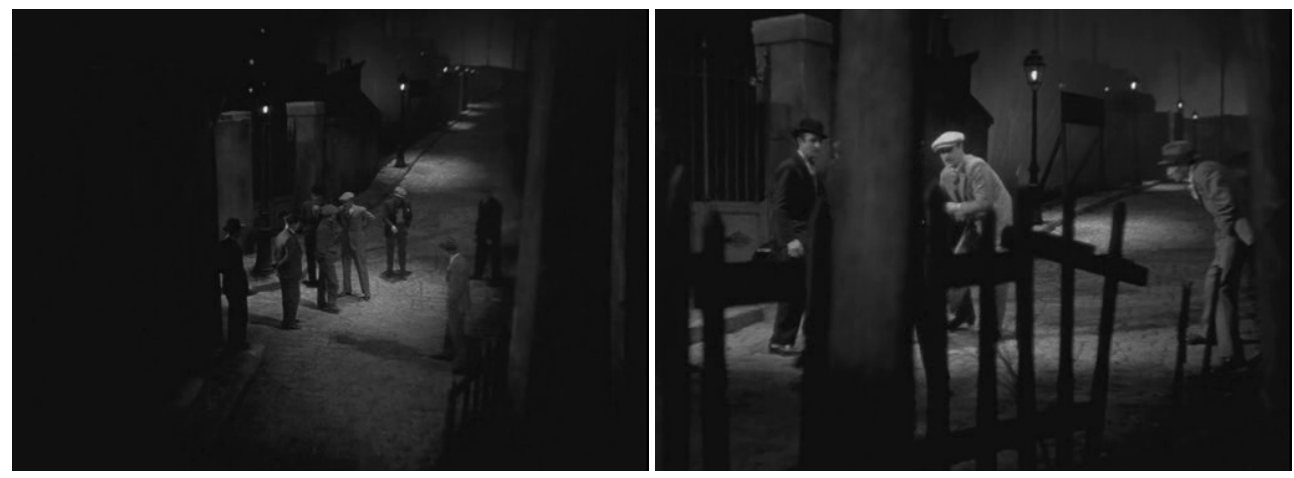

Imágenes 4 y 5. [Fuente: captura de pantalla].

Con motivo del conflicto entre el gánster y el cantante callejero, el cineasta concibe la brillante secuencia de la pelea de navajas, donde la ciudad pone en evidencia sus peligros, refugiados comúnmente en la oscuridad. Barroso (2010) la califica como excelente, con encuadres perfectos y plenos de sentido de la estética y la narrativa. Además, destaca cómo se aprovecha la "ausencia" de sonido ambiente para utilizar de fondo el ruido de un tren que ahoga el fragor de la pelea. En esta secuencia, un grupo de bandidos liderados por Fred se enfrenta a Albert por la noche -imagen 4-. La soledad de las calles en este tramo del día convierte la ciudad de París en una trampa: en ella, un tren que no podemos ver deja a su paso una estela de humo mien- 
tras su sonido enmascara los ruidos de la revuelta; no se oyen ni golpes ni gritos. Clair concibe algunos planos tras la valla que separa a los personajes del ferrocarril, con el humo y un poste también obstaculizando la mirada del espectador - imagen 5-. Este tipo de planteamiento nos lleva a citar el estudio de Stoichita (2018) sobre la intriga visual; en este caso, provocada por la relación dialéctica que se establece entre transparencia y opacidad. A continuación, Louis llega al lugar donde tiene lugar la trifulca y dispara a una farola. La oscuridad se torna absoluta. No podemos distinguir con claridad lo que ocurre. Solo es posible observar unas sombras que se mueven confusamente y, al contrario que en los momentos previos, se puede oír el revuelo que forman los personajes.

Existe en la ciudad un tipo de establecimiento muy popular: el bistrot. La fachada de cristal de uno de estos espacios - decorada con palabras como vins, liqueurs, téléphone o aperitifs - propicia un interesante juego con respecto al sonido. En primer lugar, nos referimos a la conversación que mantienen Louis y Pola dentro del local. La filmación se produce desde el exterior y el ruido de las voces se ve anulado, aunque puede apreciarse la gesticulación. El sonido solo regresa cuando Louis sale a la calle dispuesto a auxiliar a Albert. Entonces, tiene lugar la secuencia de la pelea de navajas, que al finalizar lleva a los dos amigos a refugiarse en el mismo local para esquivar a la policía. Allí, Albert pone un disco en un gramófono y suena la obertura de la opereta Caballería ligera compuesta por Franz von Suppé, que sirve de acompañamiento tanto a los primeros momentos de euforia como a la posterior pelea entre los dos personajes por el amor de Pola. Una vez más, el cineasta utiliza con gran maestría el recurso de grabar desde la calle, apreciándose tras los cristales una conversación entre Louis y Albert de la que no podemos oír ni una sola palabra.

No pueden faltar en este detallado cuadro parisino otros espacios que comúnmente se asocian a la vida en la ciudad como el salón de baile - escenario del ocio nocturno- y el hotel. Ambos establecimientos se sitúan en la misma acera y se encuentran claramente identificados desde el exterior con las palabras bal y hôtel. Concretamente, en la fachada del salón de baile destaca un corazón formado por luces y atravesado por una flecha. La iluminación también es un elemento importante de su esmerada decoración interior, que se completa con el uso de guirnaldas. Este lugar, en el que el acompañamiento musical cobra una especial relevancia, servirá como punto de encuentro para los miembros de la banda de Fred y para el resto de los personajes, todos ellos rodeados por las parejas que bailan agarradas en la pista.

Para finalizar, resulta imprescindible poner la atención en la presencia de los apartamentos parisinos. René Clair se recrea en la descripción vertical del bloque número ocho, donde Pola ocupa el ático. Las ventanas enmarcan a sus habitantes cuando la música suena en la calle y nos dejan apreciar fragmentos de la vida parisina. Del mismo modo, la vida de estos personajes será filmada desde el interior de los habitáculos que moran. El apartamento de Albert se encuentra decorado con fotografías de actividades deportivas, que, en algunos casos, podrían corresponder al Tour de Francia (imagen 6). Entre sus utensilios, destacan una guitarra y un despertador, elemento regulador de la sincronía urbana ${ }^{8}$. Una escena significativa en esta ubica-

Ferla (2012) estudia cómo entre 1925 y 1936 el cine refleja la percepción sobre la metrópolis industrial, siendo uno de los objetos de su análisis la presencia de los relojes en la pantalla. El uso de metáforas, expone, serviría a los cineastas de aquellos años tanto para ensalzar la sincronía urbana como para criticarla. 
ción es la de la discusión entre Pola y Albert en la cama. A oscuras, únicamente los diálogos pueden ofrecer información de lo que ocurre, pues visualmente solo se perciben algunos indicios de movimiento.

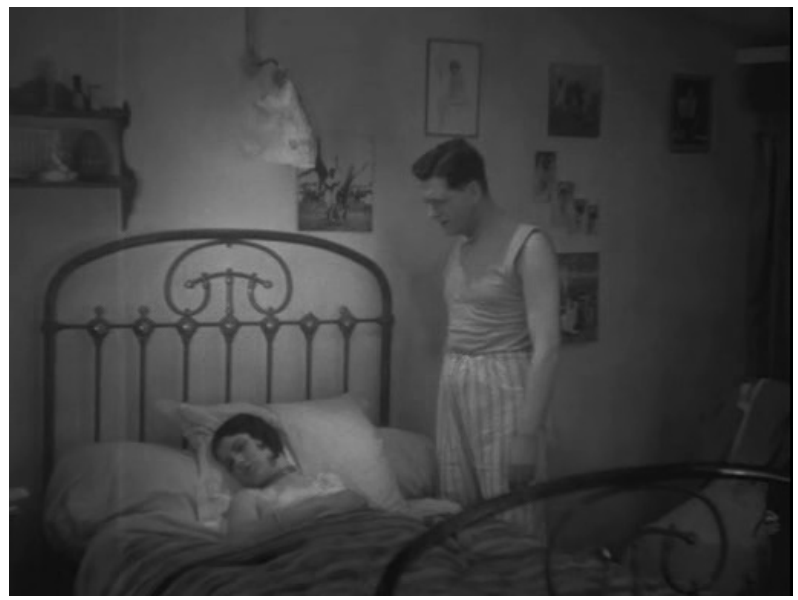

Imagen 6. [Fuente: captura de pantalla].

Otro suceso importante es el arresto del protagonista por un robo que no ha cometido: encontramos aquí un ejemplo en el que gran parte del peso dramático recae sobre los giros de la música extradiegética, que otorga a la acción un cariz cómico al más puro estilo del cine mudo. Más adelante, mientras Albert pasa una temporada encerrado en una celda, en su domicilio las flores o la barra de pan, que terminaron en el suelo el día de su detención, sufren el deterioro del paso del tiempo. Clair consigue plasmar de un modo poético en estas imágenes la sutil belleza de lo pasajero.

\section{Conclusiones}

René Clair presenta en Bajo los techos de París su particular concepción de la vida parisina — no exenta de estereotipos - y del entorno urbano a través de recreaciones ejecutadas con gran detallismo y del uso de la tecnología sonora, cuyas versátiles aplicaciones como recurso expresivo serían determinantes a la hora de plantear algunas de las escenas de mayor trascendencia de la película. En este sentido, es posible advertir cómo su ingeniosa utilización ya anunciaba una futura consolidación como herramienta imprescindible para el arte cinematográfico.

Los planteamientos sonoros concebidos en la producción del filme aportan dramatismo a la acción, intriga y ritmo. El sonido ejerce una función descriptiva, ofreciendo información relativa a las características de los lugares transitados por los personajes y a las actividades que en ellos se desarrollan - las melodías del salón de baile, el ruido del ferrocarril, etc.- - Además, a través de la música, Clair esboza cierto romanticismo sobre la imagen de la capital, aludiendo a una vida ligada a la musicalidad y a las canciones, y a la hermandad entre los ciudadanos del pueblo parisino que unen sus voces en coro en medio de la calle. Es así como moldea un paisaje sonoro que logra pasar a formar parte del conjunto de elementos que hacen de París un plató excepcional por su carácter extremadamente reconocible. 
Al mismo tiempo, el cineasta proyecta la visión de un lugar en el que existe una gran diversidad de tipos, obligados a cohabitar a pesar de las complejas circunstancias que los envuelven. En París la astucia es una herramienta para la supervivencia y el amor, un sentimiento poderoso. En este trabajo, Clair nos invita a ser testigos de cómo se desarrollan las relaciones humanas en la ciudad: bajo los tejados abuhardillados de los bloques de apartamentos cada cual crea su mundo, un mundo que se prolonga más allá de las paredes de los edificios a través de una serie de escenarios típicamente parisinos.

Sin embargo, en el París de René Clair no aparecen aquellos emblemas, como la Torre Eiffel o la catedral de Notre Dame, que hacen comúnmente conocida la ciudad. Esto es debido a que la identidad de los barrios y zonas no turísticas se construye en base a otra tipología de localizaciones - el bistrot, el hotel o el salón de baile - de distinta proyección. Estos espacios, en los que los individuos desarrollan sus actividades cotidianas, han ido consolidando su presencia en el celuloide a lo largo de los años para convertirse en señas inconfundibles de la capital francesa.

Por otro lado, la puesta en escena nos sitúa en un entorno que perfila las características de los personajes principales: ciudadanos con recursos económicos escasos y delincuentes. Todos ellos se desenvuelven a través de los distintos escenarios que recrean el ambiente de un barrio popular, en el que las relaciones vecinales toman forma en la calle, pues la vida parisina, tal y como es mostrada, está estrechamente vinculada a lo que ocurre en los sitios públicos. De igual importancia en la cinta resulta la utilización de la ambientación nocturna para narrar momentos clave de la historia: la ciudad de noche asume fuertes connotaciones ligadas al amor, el ocio o las actividades ilícitas; aunque esto no excluye que dichas ideas sean también expresadas durante el día.

Partiendo de este análisis, resulta pertinente comentar que la continua evolución del cine como disciplina artística lleva a los directores a concebir múltiples planteamientos estéticos y de contenido. Por ello, cada relato necesita disponer de unos escenarios que refuercen sus mensajes y que contribuyan a crear un universo, generalmente verosímil, en el que los espectadores puedan sumergirse. Este hecho se traduce en un constante fenómeno de transformación en los modos de representación de la metrópolis. Por otra parte, no es posible obviar que el cine, con un gran potencial en la creación del imaginario colectivo y transnacional, nos habla de múltiples facetas de la capital francesa apoyándose de manera recurrente en ideas universales y repetitivas. Dichos modos de recrear la ciudad han ido consolidándose como fórmulas exitosas basadas en clichés. Como resultado, el amor o la vida bohemia se han convertido en conceptos habitualmente evocados por escenarios como los locales de ocio, las calles de adoquines o los bloques de apartamentos de tejados abuhardillados concebidos por René Clair.

\section{Bibliografía}

Andréu, Jaime. (2001). Las técnicas de Análisis de Contenido: Una revisión actualizada. Sevilla: Fundación Centro de Estudios Andaluces.

Aubert, Michelle \& Seguin, Jean-Claude (eds.). (1996). La production cinématographique des frères Lumière. París: Bibliothèque du film. 
Barber, Stephen. (2006). Ciudades proyectadas. Cine y espacio urbano. Barcelona: Gustavo Gili.

Barroso, Miguel Ángel. (2010). Las 100 mejores películas francesas de la historia del cine. Madrid: Cacitel.

Bergfelder, Tim, Harris, Sue \& Street, Sarah. (2007). Film Architecture and the Transnational Imagination. Set Design in 1930s European Cinema. Ámsterdam: Amsterdam University Press. https://doi.org/10.5117/9789053569801

Binh, Nguyen Trong. (2005). Paris au cinéma. La vie rêvée de la Capitale de Méliès à Amélie Poulain. París: Parigramme.

Camarero, Gloria. (2013). "Escenarios para el reencuentro". En Gloria Camarero (ed.), Ciudades europeas en el cine. Madrid: Akal, 5-14.

Casetti, Francesco \& Di Chio, Federico. (1996). Cómo analizar un film. Barcelona: Paidós.

De Baecque, Antoine (ed.). (2012). Paris vu par Hollywood. París: Skira Flammarion.

Domínguez, Óscar. (1998). "Las ciudades soñadas: París y Viena”. En Cristina Carreras \& Celia Crespo (eds.), Cien años de cine: la fábrica y los sueños. Sevilla: Facultad de Ciencias de la Información, 171-180.

Douchet, Jean \& Nadeau, Gilles. (1987). Paris cinéma. Une ville vue par le cinéma de 1895 à nos jours. París: Éditions du May.

Ferla, Luis. (2012). "El maquinismo urbano hecho celuloide (1925-1936)". Cuadernos de Historia Contemporánea, núm. 34, 207-224. https://doi.org/10.5209/rev_CHCO.2012. v34.40068

Ferré, Pablo. (2001). “Ciudad, cine, comunicación”. Inmediaciones de la comunicación, núm. 3, 55-60. https://doi.org/10.18861/ic.2001.3.3

Hillairet, Prosper, Lebrat, Christian \& Rollet, Patrice (eds.). (1985). Paris vu par le cinéma d'avant-garde 1923-1983. París: Paris experimental.

Hueso, Ángel Luis. (2014). "París. Fantasía y realidad en las márgenes del Sena”. En Francisco García \& Gonzalo M. Pavés (eds.), Ciudades de cine. Madrid: Cátedra, 271-290.

Jeancolas, Jean-Pierre. (1997). Historia del Cine Francés. Madrid: Acento.

Jeanne, René \& Ford, Charles. (1997). Historia ilustrada del cine, 2. El cine sonoro (19271945). Madrid: Alianza.

Kale, Gül. (2005). "Interacción del cine y la arquitectura: mirando a través de la primera mitad del siglo XX". Bifurcaciones, núm. 3. Recuperado de http://www.bifurcaciones. cl/003/Kale.htm (Fecha de acceso: 08/02/2019).

Navarro, Alba. (2015). "La poética de los paisajes parisinos transitados por un globo rojo y un niño". En Agustín Gómez \& Ana Melendo (eds.), Paisajes visuales. La Laguna: Sociedad Latina de Comunicación Social, 43-56. https://doi.org/10.4185/cac97

Ortiz, Luz Marina. (2015). "El paisaje sonoro en En la ciudad de Sylvia (José Luis Guerin, 2007)”. En Agustín Gómez \& Ana Melendo (eds.), Paisajes visuales. La Laguna: Sociedad Latina de Comunicación Social, 135-150. https://doi.org/10.4185/cac97

Ramírez, Juan Antonio. (1993). La arquitectura en el cine. Hollywood, la Edad de Oro. Madrid: Alianza.

Schafer, Raymond Murray. (2013). El paisaje sonoro y la afinación del mundo. Barcelona: Intermedio.

Stoichita, Victor. (2018). El efecto Sherlock Holmes. Variaciones de la mirada de Manet a Hitchcock. Madrid: Cátedra.

Villanueva, Darío. (2008). Imágenes de la ciudad. Poesía y cine, de Whitman a Lorca. Valladolid: Cátedra Miguel Delibes. 
Vuillermoz, Émile. (1934). “Comment les metteurs en scène d'Hollywood se représentent Paris et ses habitants”. Pour vous. L’hebdomadaire du cinéma, núm. 277, 3.

Wimmer, Roger \& Dominick, Joseph. (2001). Introducción a la investigación de medios masivos de comunicación. México: International Thomson Editores.

Yeste, Isabel. (1994-95). "El cine como fuente documental para reconstruir la historia urbana de la ciudad". Artigrama, núm. 11, 287-296. 